\title{
Gorontalo
}

Journal of Government and Political Studies

Volume 3 - NO. 1 - April 2020

P-ISSN: 2614-2120 E-ISSN: 2614-2104

\section{Efektivitas Konstruksi Jembatan Layang Sebagai Penguraian Kemacetan dalam Kerangka Smart Mobility di Kota Yogyakarta Tahun 2019 (Studi Kasus Jembatan Layang (Fly Over) Janti)}

\author{
Luthfiana Putri Aisyah \\ Eko Priyo Purnomo \\ Aulia Nur Kasiwi \\ Departement of Government Affairs and Administration, \\ Universitas Muhammadiyah Yogyakarta \\ Jalan Brawijaya, Geblagan, Tamantirto, Kec. Kasihan, Bantul, \\ Daerah Istimewa Yogyakarta 55183 \\ luthfianaputriaisyah@gmail.com
}

Received: December 27, 2019; Revised:March 28, 2020

Accepted: April 06, 2020

\begin{abstract}
This research was conducted to determine the efforts made by the Yogyakarta city government to realize a good mobility system to overcome the congestion that occurs, one of which is at the Janti intersection, Yogyakarta. In its implementation as a breakdown of congestion, it is necessary to know the extent to which the effectiveness and impact arising from the construction of the Janti fly over. This research is a type of descriptive qualitative research that presents factual and systematic data. Data collection is done by observation and literature review in order to dig up information and process and draw conclusions as a qualitative research method. The urgency of the embodiment of smart cities in other cities in Indonesia is the imbalance of population growth with the development of industrialization. Technology-based smart mobility systems are designed to regulate the movement of public transportation and traffic management in a city. The application of information technology aims to have a smooth and convenient impact on traffic. The results of this study explain that the Janti fly over is the primary arterial road that connects the three Janti intersections. This development has an effect on traffic circulation, which is reducing the level of vehicle density and congestion. Not only the positive impact but the negative impact is also felt by residents who live around the fly over, especially since since 2017 the road closure has been put under the Janti fly over.The results of this study can certainly be an evaluation material for the government in reviewing the application of policies that have been made. Given the social and economic impacts that occur due to the construction and closure of the road under the Janti fly over.
\end{abstract}

Keywords: smart mobility; fly over; traffic jam

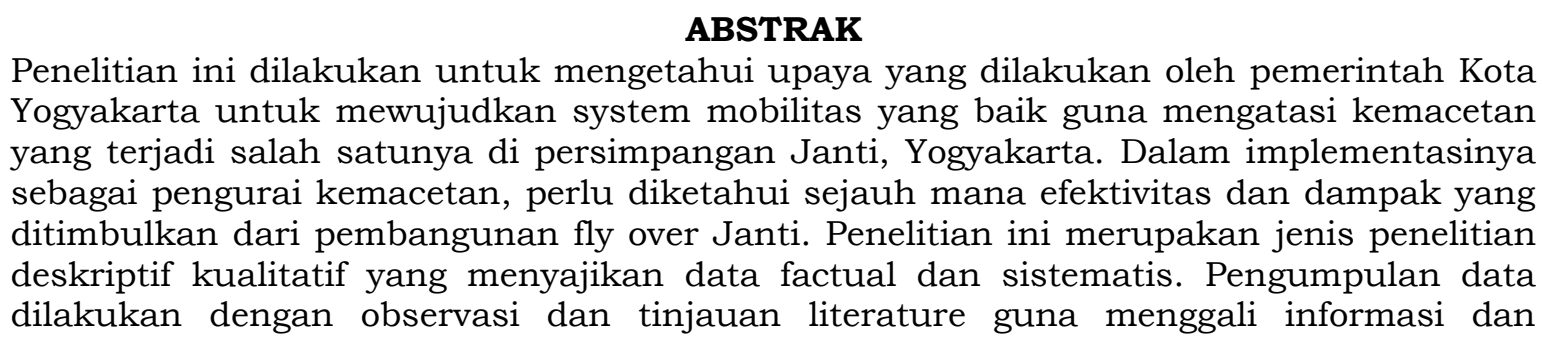


mengolah lalu menarik kesimpulan sebagaimana metode penelitian kualitatif dilakukan. Urgensi perwujudan kota cerdas di kota-kota lainnya di Indonesia adalah tidak seimbangnya pertumbuhan konsentrasi penduduk dengan perkembangan industrialisasi. System smart mobility yang berbasis teknologi dirancang untuk mengatur pergerakan transportasi public dan traffic management suatu kota. Penerapan teknologi informasi ini bertujuan untuk memberikan dampak kelancaran dan kenyamanan dalam berlalu lintas. Hasil penelitian ini menjelaskan bahwa fly over Janti merupakan jalan arteri primer yang menjadi penghubung simpang tiga Janti. Pembangunan ini berpengaruh pada sirkulasi lalu lintas yaitu pengurangan tingkat kepadatan kendaraan dan kemacetan. Tak hanya dampak positif namun dampak negative juga dirasakan warga yang bermukim di sekitar fly over terlebih setelah sejak tahun 2017 mulai diberlakukan penutupan jalan di bawah fly over Janti.

Hasil dari penelitian ini tentunya bisa menjadi bahan evaluasi bagi pemerintah dalam mengkaji penerapan kebijakan yang telah dibuat. Mengingat dampak sosial dan ekonomi yang terjadi akibat adanya pembangunan dan penutupan jalan di bawah fly over Janti tersebut.

\section{Keywords: smart mobility; fly over; lalu lintas}

\section{PENDAhuluan}

Pertumbuhan penduduk di kawasan urban semakin meningkat karena berbagai asumsi masyarakat mengenai kemudahan akses dalam berbagai bidang yang menyebabkan perkotaan menjadi magnet urbanisasi bagi masyarakat (Hasibuan \& Sulaiman, 2014). Seiring bertambahnya jumlah penduduk maka bertambah pula tingkat kemacetan suatu kota. Salah satu penyebab kemacetan lalu lintas yang terjadi di sebagian besar persimpangan jalan Kota Yogyakarta diakibatkan oleh semakin bertambahnya volume kendaraan yang melintas dan mengakibatkan kemacetan. Menurut Ditlantas Polda DIY (Handito, 2016) sampai bulan September 2016 ada sebanyak 84.312 unit kendaraan bermotor baru di Kota Yogyakarta. Maka untuk mengendalikan pergerakan suatu kota dan masyarakatnya dalam kerangka smart city, (Fritz Akhmad Nuzir, 2015) menyatakan bahwa aspek yang harus dicapai adalah dengan optimalisasi system mobilitas yang mampu memenuhi kebutuhan dan harapan masyarakat.

Penelitian ini akan membahas mengenai penerapan smart city di Kota Yogyakarta dengan focus pembahasan indicator smart mobility. (Fritz Akhmad Nuzir, 2015) menyebutkan bahwa system mobilitas yang mampu memenuhi kebutuhan dan harapan masyarakat itu mencakup aspek kelancaran, kenyamanan, dan keamanan. Sedangkan (Hariani, Safina, \& Syarifuddin, 2017) menyebutkan bahwa indicator dari smart mobility itu sendiri adalah pengadaan alat transportasi, infrastruktur, serta system pelayanannya. Salah satu upaya yang dilakukan oleh pemerintah Kota Yogyakarta untuk mewujudkan system mobilitas yang baik guna mengatasi kemacetan yang terjadi salah satunya di persimpangan Janti adalah dengan dibangunnya infrastruktur jembatan layang (fly over) Janti, Yogyakarta. Berdasarkan penelitian sebelumnya, (Janu, 2010) menyebutkan bahwa pada implementasinya, pembangunan fly over ini mengakibatkan berbagai dampak bagi masyarakat sekitar konstruksi tersebut. Salah satunya adalah memicu munculnya gelandangan dan gerobak kaki lima yang membuat kumuh kawasan di bawah fly over.

Yogyakarta merupakan salah satu contoh kota di Indonesia yang sudah menerapkan konsep smart city. (Nilma, 2015) menyebutkan bahwa pada tahun 2015, ada sebanyak 42.629 pelajar dan mahasiswa pendatang di Kota Yogyakarta. City branding yang dimiliki Kota Yogyakarta ini menunjukkan 
adanya daya tarik bagi pelajar luar daerah untuk menuntut ilmu di kota pelajar ini. Masifnya penggunaan teknologi informasi pada era revolusi industry 4.0 ini salah satunya dalam sector transportasi menjadi satu indicator penting dalam perwujudan smart mobility. Sehingga pergerakan masyarakat bisa dinilai dengan adanya transportasi dan infrastruktur jalan yang memadai.

Pengintegrasian system transportasi ini harus mencakup aspek kenyamanan, kelancaran, keamanan, dan keselamatan lalu lintas. Menurut (Fritz Akhmad Nuzir, 2015) parameter smart mobility bisa dilihat dari keberhasilan pemerintah dalam program pembangunan infrastruktur jalan dan pengadaan transportasi umum yang berkualitas. Upaya penguraian kemacetan di berbagai persimpangan jalan di Kota Yogyakarta khususnya di daerah Janti ini ditempuh dengan pembangunan fly over (Raharja et al., 2017).

Berdasarkan latar belakang masalah di atas, maka rumusan masalah dalam penelitian ini adalah (1) Bagaimana efektivitas konstruksi fly over Janti sebagai pengurai kemacetan dalam kerangka smart mobility di Kota Yogyakarta, dan (2) Apa saja dampak social yang ditimbulkan dari pembangunan kontruksi fly over Janti, Yogyakarta jika mengacu pada indicator smart mobility dalam smart city. Tujuan dari penelitian ini adalah untuk mengetahui tingkat efektivitas pembangunan fly over sebagai pengurai kemacetan, serta apa saja dampak social yang ditimbulkan dari pembangunan konstruksi fly over Janti, Yogyakarta jika mengacu pada indicator smart mobility dalam smart city.

Pengoptimalan konsep smart city dilakukan dengan berbagai cara. Salah satu upaya untuk mencapai target yang dilakukan oleh pemerintah dan organisasi non-pemerintah adalah dengan melibatkan warga, kolaborasi sektor publik dan swasta untuk bergabung dalam pengembangan kota pintar (Purnomo, Obisva, \& Astutik, 2019). Seiring dengan perkembangan kota yang pesat (Jon, 1999), mengelompokkan masalah yang terjadi di beberapa kota besar, terutama kota Yogyakarta. Permasalahan ini menjadi semakin kompleks. Beberapa masalah itu seperti munculnya kemacetan, kenakalan remaja, kerusakan infrastruktur, dan masalah lainnya yang kian menjadi masalah yang semakin klasik. Pemerintah tentu dituntut untuk menjadi organisasi yang dapat memaksimalkan potensi daerahnya tanpa mengesampingkan beberapa masalah yang muncul di daerahnya. Salah satu solusi efektif dalam menyelesaikan masalah ini adalah menerapkan konsep Kota Cerdas. Komunitas yang lebih luas memandang kota pintar sebagai terbatas pada berapa banyak kota menghasilkan aplikasi yang dapat diakses oleh publik. Namun lebih dari itu penerapan kota pintar membutuhkan banyak interaksi dari masyarakat luas dengan kalangan pemerintah daerah terkait.

Teknologi dan infrastruktur adalah pusat pembangunan suatu kota cerdas, tetapi hal ini sejauh ini hanya berjalan tanpa perencanaan dan visi yang terkoordinasi (Papa \& Lauwers, 2015). Sistem mobilitas perkotaan yang benarbenar pintar sudah semestinya mampu memanfaatkan teknologi untuk meningkatkan kualitas kehidupan dan memudahkan akses dalam pengambilan keputusan. Di atas segalanya, sistem ini bersifat sosial, lingkungan, dan finansial berkelanjutan. Selanjutnya, strategi pintar dalam banyak kasus tidak terkait dengan tujuan yang lebih komprehensif. Dengan kata lain, inovasi dalam mobilitas harus mencakup keberlanjutan dan kualitas tujuan perencanaan hidup dalam penerapannya. 
(Monoarfa, 2012) Menyebutkan bahwa dalam Keputusan Menpan Nomor 81 tahun 1993 telah diatur tentang pemmemberian pelayanan public harus mengandung unsur-unsur sebagai berikut:

"Pertama, Hak dan kewajiban bagi pemerintah maupun masyarakat harus diketaui dengan jelas dan masing-masing darinya mengetahui dengan jelas.

Kedua, Setiap bentuk pelayanan umum harus disesuaikan dengan kondisi, kebutuhan dan kemampuan masyarakat untuk membayar, berdasarkan ketentuan peraturan perundang-undangan yang berlaku dengan tetap berpegang pada efisiensi dan efektivitas.

Ketiga, Mutu, proses, dan hasil pelayanan umum harus diupayakan agar memberi keamanan, kenyamanan, kelancaran, dan kepastian hukum yang dapat dipertanggungjawabkan.

Keempat, Apabila pelayanan umum yang diselenggarakan oleh instansi pemerintah terpaksa harus mahal, maka instansi pemerintah yang bersangkutan berkewajiban memberi peluang kepada masyarakat untuk ikut menyelenggarakannya sesuai dengan peraturan perundang-undangan yang berlaku."

Permasalahan klasik yang timbul pada suatu perkotaan adalah kemacetan. (Aryandi \& Munawar, 2014) mengemukakan bahwa kemacetan lalu lintas terjadi karena suatu persimpangan berdekatan dengan pusat keramaian, karena konflik pergerakan yang terjadi antar kendaraan yang datang dari tiap kaki simpang. Untuk menyikapi masalah tersebut, Dinas Perhubungan Kota Yogyakarta telah menerapkan penggunaan software vissim untuk memantau kondisi simpang dan meneliti volume lalulintas. Software vissim digunakan untuk kebutuhan simulasi lalu lintas multi moda seperti skema driving behavior, vehicle, dan traffic controller. Sehingga untuk menciptakan sustainable mobility, harus memperhatikan aksesibilitas, agar arus lalu lintas dapat dikendalikan sehingga meminimalisir kemacetan.

Hal yang sama telah diterapkan di Kota Surabaya. Kemacetan di ruas jalan utama Kota Surabaya diatasi dengan adanya sistem navigasi kota yang dapat memberikan kemudahan dalam penginformasian jalan alternatif untuk mencapai waktu perjalanan tercepat ataupun menghindari kemacetan sehingga sangat membantu masyrakat untuk sampai ke tempat tujuan dengan aman (Shiddekh \& Suryani, 2018).

Selain penggunaan software untuk memantau keadaan lalu lintas, pemerintah juga menerapkan kebijakan - kebijakan guna mencapai goals dari smart mobility. Contoh lainnya adalah kebijakan ganjil genap yang diterapkan di DKI Jakarta. Penerapan Electronic Road Price (ERP) dan penaikan biaya pajak dilakukan untuk mengurangi kemacetan dan polusi secara drastic (Arman Syah Putra, n.d.). Pada penelitian ini, kebijakan ganjil genap telah berhasil diterapkan di sejumlah besar jalan protokoler di Kota DKI Jakarta. Penerapan system ini bertujuan untuk membatasi kendaraan - kendaraan dengan ketentuan tertentu sehingga menghindari adanya kemacetan panjang yang menjadi masalah besar di ibukota ini. Pada praktiknya, kebijakan ganjil genap ini masih menuai pro dan kontra karena adanya anggapan ketidaksetaraan hak pengguna jalan. Kemacetan pada jam sibuk ini masih terus dikaji pemerintah untuk memcahkan masalah tersebut. Meskipun ketersediaan transportasi public dan infrastruktur jalan yang sudah terjamin, namun permasalahan besar lainnya terjadi pada 
kemacetan yang belum teratasi. Sehingga konsep smart city khususnya dalam aspek smart mobility di DKI Jakarta belum optimal.

(Fauzan, 2017) mengemukakan bahwa implementasi kota cerdas di Kota Bandung dirancang dengan membentuk Dewan Pengembangan Bandung Kota Cerdas atau biasa disebut dengan Dewan Smart City. Dewan smart city terdiri dari berbagai elemen masyarakat baik pemerintah, stakeholder maupun akademisi. Dalam menjalankan tugasnya, dewan smart city memiliki progam seperti perbaikan fasilitas internet bagi seluruh kantor dinas, ada juga program populis yang bertujuan untuk mendapatkan dukungan dan partisipasi dari masyarakat, serta pengawasan secara real time proyek-proyek pembangunan yang ada di kota. Tidak hanya itu, program dari dewam smart city juga mencakup pengawasan titik-titik kemacetan yang langsung terhubung dengan Command Center. Sehingga pemerintah Kota Bandung memiliki acuan dalam pembuatan program penguraian kemacetan lalu lintas.

Lain halnya dengan Kota Bandung, urgensi perwujudan kota cerdas di Surabaya maupun kota-kota lainnya di Indonesia adalah tidak seimbangnya pertumbuhan konsentrasi penduduk dengan perkembangan industrialisasi (Shiddekh \& Suryani, 2018). Mengingat kota menjadi medan magnet urbanisasi, maka salah satu inovasi publik yang dibuat pemerintah adalah breakthrough untuk mengatasi kemacetan di sektor publik. Dengan demikian maka sektor publik dapat menjadi sektor yang mampu mengakomodasi dan merespons dengan cepat perubahan yang selalu terjadi di masyarakat.

Dalam rangka pembangunan smart city di Kota Medan, (Hariani et al., 2017) menemukan dalam penelitiannya bahwa telah diterapkan sebuah alat serta aplikasi Intelligent Transportation System (ITS) yang digunakan untuk membantu masyarakat dalam pembangunan aspek smart mobility terutama untuk mengetahui kondisi jalan raya. Dalam penerapan kebijakan smart transportation, tujuannya adalah agar lalu lintas dapat dioptimalkan pada seluruh route alternatif yang ada, sehingga kemacetan dapat dihindari atau dikurangi. Konsep smart city yang diterapkan di Kota Medan terutama dalam aspek smart mobility berbasis ICT untuk memudahkan masyarakat dalam mengakses informasi dan mendapatkan layanan yang cepat khususnya untuk moda transportasi dengan adanya system yang terintegrasi di Kota Medan.

Penerapan smart city di Kota Tangerang Selatan dilakukan pemerintah dengan membuat inovasi baru Area Traffict Control System (ATCS), yakni program yang secara otomasis mengatur operasional traffict light agar perannnya dapat optimal dalam mengatur lalu lintas (Gunartin, 2018). Sistem ini dilengkapi CCTV yang di link kan dengan operator Dinas Perhubungan sehingga operator dapat memantau kondisi di lapangan secara otomatis dan menangani permasalahan yang terjadi.

Upaya lainnya yang dilakukan untuk mencegah dan mengurangi kemacetan lalu lintas di Kota Pontianak adalah dengan memperluas lebar jalan, membatasi jumlah dan volume kendaraan, serta penerapan peraturan yang lebih ketat (Wini Mustikarani \& Suherdiyanto, 2016). System smart mobility yang berbasis teknologi dilakukan untuk mengatur pergerakan transportasi public dan traffic management. Penerapan teknologi informasi ini bertujuan untuk memberikan dampak kelancaran dan kenyamanan dalam berlalu lintas. Arah pembangunan infrastruktur suatu kota diwujudkan melalui penguatan sistem 
perencanaan infrastruktur dan peningkatan konsistensi pengendalian pembangunan infrastruktur (Purnomowati \& Ismini, 2014).

Berdasarkan literature yang telah dijabarkan di atas maka perbedaan penelitian terdahulu dengan penelitian ini terdapat pada focus pembahasan smart mobility. Penelitian ini lebih berfokus pada pembahasan efektivitas dari pembangunan infrastruktur fly over sebagai inovasi untuk mengatasi permasalahan kemacetan. Selain itu, penelitian ini juga membahas mengenai dampak social apa saja = yang terjadi akibat adanya pembangunan fly over Janti. Keberadaan infrastruktur fly over ini menjadi salah satu indicator dalam perwujudan mobilitas yang baik karena indicator smart mobility menjadi salah satu indicator yang ada dalam konsep smart city. Sehingga perlu diketahui sejauh mana efektivitas pengadaan bangunan fly over yang mulanya bertujuan sebagai pengurai kemacetan di persimpangan Janti tersebut.

\section{METODE PENELITIAN}

Penelitian ini merupakan jenis penelitian deskriptif kualitatif yang bertujuan untuk membuat deskripsi secara factual dan sistematis mengenai fakta-fakta dari objek yang diteliti. Metode penelitian yang digunakan dalam penelitian ini adalah metode kualitatif. Penelitian kualitatif yaitu penelitian yang memberi gambaran secara cermat mengenai individu atau kelompok tertentu yang tentang keadaan dan gejala yang terjadi (Koentjaraningrat, 1993:89).

Jenis penelitian ini sesuai dengan data yang akan diperoleh yaitu data berupa kata -kata yang berasal dari observasi dan tinjauan literatur. Sehingga penelitian ini merupakan jenis penelitian lapangan yaitu suatu prosedur pemecahan masalah yang dilakukan dengan menggambarkan keadaan subjek atau objek penelitian secara actual dan faktual (Nawawi, 1998). Jenis data pada penelitian ini adalah data primer dan sekunder. Data primer diperoleh melalui observasi yang dilakukan langsung di sekitar kawasan fly over Janti, Yogyakarta. Pengumpulan data sekunder diperoleh melalui tinjauan literatur dengan melakukan penelusuran buku teks, jurnal, artikel, referensi yang berkaitan dengan penelitian ini, dan penelitian terdahulu yang berkaitan dengan penelitian ini.

Teknik pengumpulan data pada peneilitian ini menggunakan observasi dan tinjauan literatur. Peneliti melakukan observasi dengan mengamati keadaan social dan tinjauan literatur dilakukan dengan membaca buku-buku yang dapat membantu peneliti melakukan penelitian untuk memperoleh data yang relevan (Sulistyo-Basuki, 2006: 220). Tinjauan literatur digunakan sebagai bagian dari komponen teknik pengumpulan data. Peneliti akan mengolah data secara sistematis dan membaca literature yang relevan dengan penelitian dalam sebuah subjek, kemudian mengorganisasi, mensintesis, menilai secara kritis informasi tersebut, dan menyimpulkan sebuah konsep.

Analisis data yang dilakukan dalam penelitian ini dilakukan secara induksi - interpretasi - konseptualisasi. Induksi adalah laporan lapangan yang detail, kemudian interpretasi adalah makna tersembunyi dari hasil penelitian di lapangan yang kemudian akhirnya didapatkan suatu konsep yang disebut konseptualisasi. Untuk menjawab pertanyaan dalam penelitian ini maka perolehan data yang dilakukan melalui observasi dan studi pustaka kemudian dianalisis menggunakan kemampuan nalar dengan menghubungkan fakta, data, 
dan informasi. Sehingga analisa tersebut diharapkan dapat memunculkan gambaran dan mengungkapkan masalah penelitian.

\section{HASIL DAN PEMBAHASAN}

Pembangunan fly over Janti berpengaruh pada sirkulasi lalu lintas yaitu pengurangan tingkat kepadatan kendaraan dan kemacetan. Perwujudan smart city di Kota Yogyakarta, khususnya dalam indicator smart mobility, sejatinya belum mampu mencapai efektivitas. Pembangunan fly over Janti memang bertujuan untuk mengurangi kemacetan, namun hal ini juga menimbulkan berbagai dampak buruk bagi masyarakat yang tinggal di sekitar fly over. Berbicara mengenai konsep smart city, maka sebuah kota harus mampu mengatur kotanya menjadi sebuah kota yang mampu memberikan pelayanan, kenyamanan dan keamanan bagi masyarakatnya serta membuat sebuah jaringan yang terkoneksi satu sama lain. Aspek kenyamanan bagi pengendara di jembatan layang Janti memang sudah tercapai karena sudah terhindari dari adanya kemacetan lalu lintas. Namun aspek kenyamanan bagi warga yang bertempat tinggal di sekitar jembatan layang nampaknya belum mampu terealisasi jika melihat kondisi infrastruktur dan keadaan Kawasan di bawah fly over yang kumuh dan matinya sector ekonomi di sekitar fly over Janti.

Pembangunan konsep smart city di Kota Yogyakarta terus dilakukan guna mencapai tatanan masyarakat yang harmonis dengan adanya kemudahan pelayanan public dan sinergisitas antara pemerintah, masyarakat, dengan stakeholder yang ada. Keberadaan smart city merupakan merupakan perwujudan dari amanat undang-undang, yakni mencerdaskan kehidupan bangsa. Maka kota yang cerdas sudah semestinya mampu memberikan solusi untuk mengatasi permasalahan-permasalahan yang dihadapi suatu kota (Haryadi, 2018).

Untuk mewujudkan sebuah kota yang cerdas maka terdapat indicator indikator yang harus dicapai, indicator tersebut menurut (Griffinger, 2007) adalah sebagai berikut:

\section{Smart People}

Sebagai sumber daya manusia yang memiliki peran major dalam pengembangan konsep smart city, maka 'people' dalam sebuah smart city harus memiliki sebuah modal social. Kemajemukan etnis dan social dalam masyarakat harus mampu mendorong adanya keterbukaan pemikiran.

\section{Smart Economy}

Sebuah kota yang menerapkan konsep smart city harus memiliki perekonomian yang berdaya saing. Maka dari itu perlu adanya kemampuan kewirausahaan yang inovatif untuk membuat citra perekonomian dan fleksibilitas pasar.

\section{Smart Governance}

Terwujudnya pelayanan public yang baik, transparan, dan akuntabel menjadi indicator penting untuk mencapai keberhasilan dari smart governance. Selain itu, smart governance juga mengacu pada prinsip masyarakat yang partisipatif dalam proses pengambilan keputusan dalam pemerintahan. 


\section{Smart Mobility}

Ketercapaian smart mobility ditandai dengan adanya mobilitas cerdas yang mampu menunjang aksesibilitas dalam system transportasi berkelanjutan dengan adanya infrastruktur yang berbasis teknologi informasi dan komunikasi.

\section{Smart Environment}

Mengacu pada manajemen sumber daya alam suatu kota. Tidak hanya itu, melainkan pengelolaan sampah dan pengadaan ruang terbuka hijau juga merupakan hal penting dalam konsep smart environment.

\section{Smart Living}

Mengarah pada kualitas hidup masyarakat. Hal ini dapat dicapai dengan pengadaan fasilitas public dalam bidang tendidikan, kesehatan, dan kualitas perumahan. Selain itu juga pengembangan fasilitas wisata dan budaya untuk menambah daya tarik wisata.

Lebih jauh mengenai smart mobility, bahwa perencanaan mobilitas suatu kota harus dimulai dari tatanan paling awal. Adanya sebuah kota harus diiringi dengan keberadaan infrastruktur jalan yang menjadi akses mobilitas kota (Gehl, 2013). Perhatian khusus dalam ranah public terletak pada penciptaan ruang public yang berkualitas, seperti trotoar, termasuk jalan setapak, taman, jalanan, dan gedung-gedung public. Definisi tata ruang dalam sebuah kota dilihat dari keadaan kota yang mampu menciptakan ruang public yang sesuai dengan keadaan dan kebutuhan masyarakatnya.

(Battey, et al., 2012) menyatakan bahwa smart city dan smart mobility merupakan pemanfaatan Teknologi Informasi dan Komunikasi berdasarkan kebutuhan masyarakat. Garis besar pemanfaatan Teknologi Informasi dan Komunikasi dalam ranah smart city ini didasarkan pada pemanfaatan untuk membuat sebuah inovasi baru untuk membangun sebuah system mobilitas cerdas dan system transportasi yang sesuai dengan arah kebijakan Indonesia.

Tabel 1: Data Jenis Kendaraan Bermotor di Indonesia

\begin{tabular}{|lr|r|r|}
\hline \multirow{2}{*}{ Jenis Kendaraan Bermotor } & \multicolumn{3}{c|}{} \\
\cline { 2 - 4 } & \multicolumn{1}{c|}{$\mathbf{2 0 1 5}$} & \multicolumn{1}{l}{$\mathbf{2 0 1 6}$} & \multicolumn{1}{c|}{$\mathbf{2 0 1 7}$} \\
\hline Mobil Penumpang & 13480973 & 14580666 & 15493068 \\
\hline Mobil Bis & 2420917 & 2486898 & 2509258 \\
\hline Mobil Barang & 6611028 & 7063433 & 7523550 \\
\hline Sepeda motor & 98881267 & 105150082 & 113030793 \\
\hline Jumlah & 121394185 & 129281079 & 138556669 \\
\hline
\end{tabular}

Source: bps.go.ig

Berdasarkan data Badan Pusat Statistik (BPS) mengenai Jenis kendaraan bermotor yang ada di Indonesia pada tahun 2015, dapat dilihat bahwa jumlah kendaraan bermotor baik mobil penumpang, mobil bus, mobil barang, maupun sepeda motor selalu mengalami kenaikan setiap tahunnya. Kenaikan jumlah 
sepeda motor sangat signifikan terjadi pada tahun 2017. Hal inilah yang menjadi biang kemacetan pada lalu lintas yang ada di wilayah perkotaan di Indonesia. Semakin meningkatnya volume kendaraan di seluruh kota yang ada di Indonesia mengakibatkan kota menjadi macet dan perlu adanya inovasi baru dari pemerintah untuk mengatasi permasalahan tersebut. Kepadatan arus lalu lintas juga disebabkan oleh jam jam sibuk dan kondisi jalan yang merupakan bentuk jalan persimpangan. Hal ini dapat dilihat dari banyaknya kemacetan yang terjadi pada setiap kota yang lebih banyak terjadi di persimpangan. Maka pemerintah memiliki tantangan untuk mengatasi permasalahan ini. Telebih jika suatu kota ingin menerapkan konsep smart city. Karena sejatinya smart city adalah membangun sebuah kota yang terintegrasi dengan jaringan internet yang di dalamnya juga mencakup indicator-indikator smart yang salah satunya adalah smart mobility. Artinya, kota yang menerapkan smart mobility harus memenuhi standar dalam kemudahan aksesibilitas dan mobilitas public.

\begin{tabular}{|c|c|c|c|c|}
\hline \multirow{3}{*}{ Jenis Kendaraan } & \multicolumn{4}{|c|}{$\begin{array}{l}\text { Jumlah Kendaraan Bermotor yang Terdaftar menurut Jenisnya di D.I. } \\
\text { Yogyakarta }\end{array}$} \\
\hline & $\begin{array}{l}\text { Bukan Umum } \\
\text { Perorangan }\end{array}$ & $\begin{array}{c}\text { Umum } \\
\text { Perusahaan }\end{array}$ & Pemerintah & Jumlah \\
\hline & 2015 & 2015 & 2015 & 2015 \\
\hline Mobil Penumpang & 199858 & 3598 & 3202 & 206658 \\
\hline 1. Sedan & 39471 & 1287 & 340 & 41098 \\
\hline 2. Station Wagon & 30258 & 941 & 1255 & 32454 \\
\hline 3. Mini bus & 115676 & 1357 & & 118403 \\
\hline 4. Jeep & 14453 & 13 & 237 & 14703 \\
\hline \multicolumn{5}{|l|}{ 5.Lain-lain } \\
\hline Mobil Bus & 7553 & 3508 & 497 & 11558 \\
\hline 1. Bus Biasa & 232 & 2134 & 274 & 2640 \\
\hline 2. Mikro bus & 7321 & 1374 & 223 & 8918 \\
\hline 3. Bus Tingkat & & & & \\
\hline
\end{tabular}

Source: Yogyakarta.bps.go.id

Berdasarkan data jumlah kendaraan bermotor di Daerah Istimewa Yogyakarta di atas, dapat diketahui bahwa kepemilikan kendaraan bermotor didominasi oleh kendaraan bukan umum/ perorangan. Jika dikaitkan dengan data kenaikan jumlah kendaraan bermotor di Indonesia, maka semakin banyak jumlah kendaraan tersebut diakibatkan oleh kepemilikan kendaraan bermotor bagi perorangan. Arus urbanisasi di perkotaan yang semakin meningkat mengakibatkan padatnya jumlah penduduk dan juga kepemilikan kendaraan bermotor. Hal ini menjadi masalah jika tidak diimbangi dengan pengadaan infrastruktur jalan yang memadai. Banyaknya kendaraan bermotor yang selalu meningkat setiap tahunnya akan berpengaruh dengan system mobilitas perkotaan. Dalam pengadaan infrastruktur jalan yang memadai pun juga harus memperhatikan dampak social bagi masyarakat. 
Menurut Rencana Tata Ruang dan Wilayah Kabupaten Sleman Tahun 2011-2031 Ayat 1 Huruf B, Jalan Janti merupakan jalan arteri primer yang meliputi perbatasan Kabupaten Sleman, Kabupaten Bantul, hingga sampai pada simpang pertigaan Maguwoharjo, Sleman. Berdasarkan pada peraturan pemerintah bahwa lebar jalan arteri primer adalah minimal 11 meter dengan dua jalur, maka jalan Janti dapat dikatakan sebagai jalan arteri primer karena kini lebar jalan mencapai 27,5 meter (Boru, n.d.). Jalan arteri primer adalah jalan utama pada suatu perkotaan dengan kapasitas yang tinggi dengan fungsi mengirimkan lalau lintas pada jalur lingkar untuk pendistribusian pelayanan barang dan jasa dalam lingkup lokal nasional.

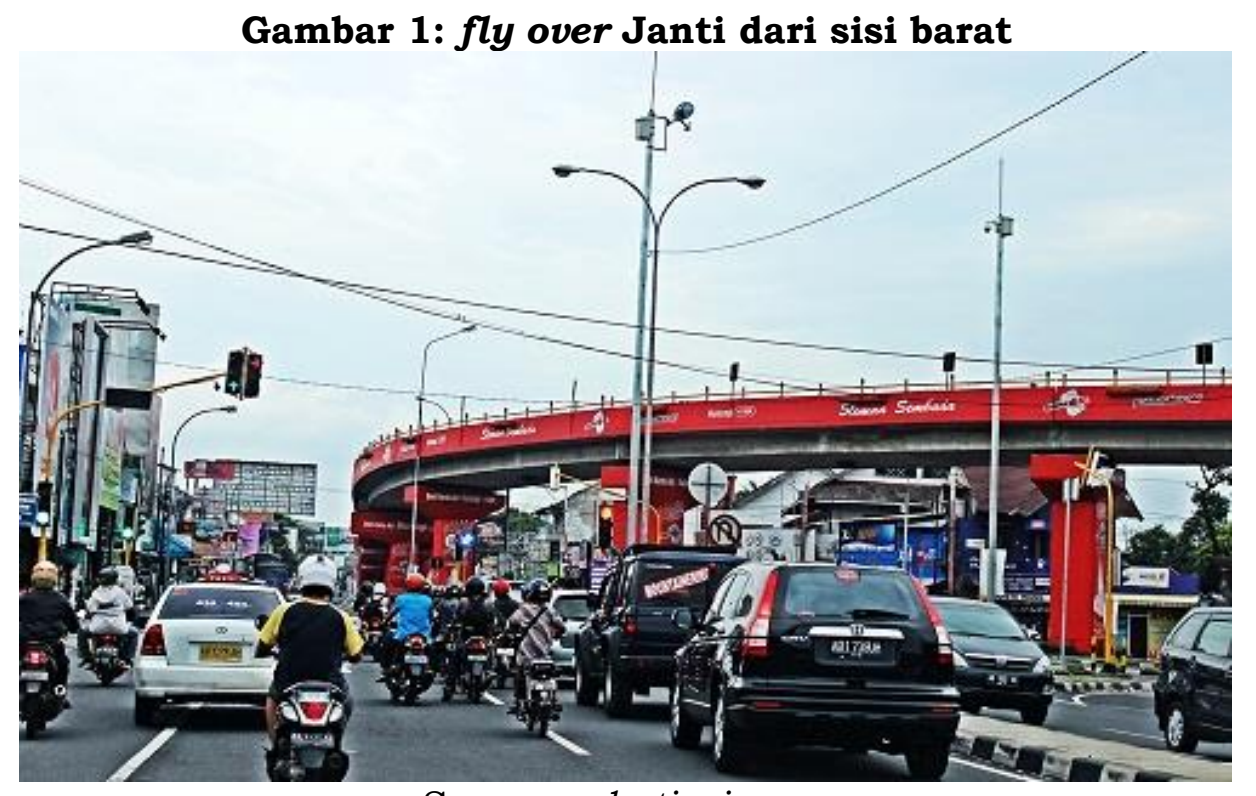

Source: sobatjogja.com

Jembatan layang Janti tepat berada di pertigaan persimpangan Janti yang menghubungkan jalan Babarsari, Maguwoharo, dan perbatasan Bantul. Keadaan wilayah Kota Yogyakarta sebagai Kota Pendidikan dan Kota wisata menjadikan Kota Yogyakarta memiliki tingkat kepadatan lalu lintas yang tinggi terutama pada ruas-ruas jalan utama. Keberadaan moda transportasi darat seperti mobil, motor, truk dan bus turut memberi kontribusi terhadap kemacetan yang terjadi di area jalan Janti.

Kepadatan lalu lintas yang tinggi mengakibatkan kemacetan pada pertigaan (junction) yang menjadi jalan arteri primer ini, terlebih sejauh kurang lebih 450 meter dari persimpangan Janti terdapat persimpangan sebidang dengan jalan kereta api. Hal ini yang mendasari pembangunan fly over Janti dengan harapan bias mengurai kemacetan yang diakibatkan penumpukan kendaraan di pertigaan yang sebidang dengan jalan kereta api disaat kereta sedang melintas. Mengingat jalur kereta api ini merupakan single track dengaan volume lintasan sebanyak 88 lintasan/hari. Oleh sebab itu, persimpangan Janti sangat memerlukan aadanya penguraian kemacetan yang kemudian diimplementasikan dengen pembangunan jembatan layan (fly over). Departemen Permukiman dan Prasarana Wilayah telah berhasil mewujudkan rencana pembangunan fly over pertama di Kota Yogyakarta yang dibangun dengan menghabiskan dana sebesar Rp. 23 M. Fly over sejauh 1.250 meter ini dibangun 
secara bertahap mulai dari pembangunannya yang dilaksanakan pada tahun anggaran 1998/1999 lalu dilakukan pelebaran ruas jalan secara bertahap setelahnya.

Pembangunan fly over Janti telah berhasil mengatasi kemacetan, hal ini dibuktikan dengan dialihkannya jalur yang menghubungkan Jl. Gedongkuning dengan J1. Laksda Adisutjipto dan J1. Solo Yogyakarta yang semula lewat jalur bawah melintasi jalur kereta api. Saat ini tidak ada lagi kendaraan yang melintas di bawah jembatan layang tersebut melainkan dialihkan untuk melewati fly over. Tetapi, hal ini juga menjadi suatu dampak buruk bagi masyarakat khususnya yang memiliki berbagai usaha yang berada di sekitar fly over Janti.

Keberadaan fly over Janti sebagai jalan arteri primer ini menjadi penghubung simpang tiga Janti. Terhitung sejak tahun 2017 penutupan jalan di bawah fly over Janti mulai diberlakukan. Direktur Perkeretaapian Kementerian Perhubungan (Edi, 2017) menyatakan bahwa penutupan jalan tersebut didasari atas dua hal, yang pertama adalah keberadaan fly over yang seharusnya digunakan sebagaimana mestinya, dan yang kedua adalah alasan keamanan, mengingat jumlah kereta api yang berlalu lalang setiap harinya.

\section{Gambar 2; Penutupan Jalan di Bawah Fly Over Janti}

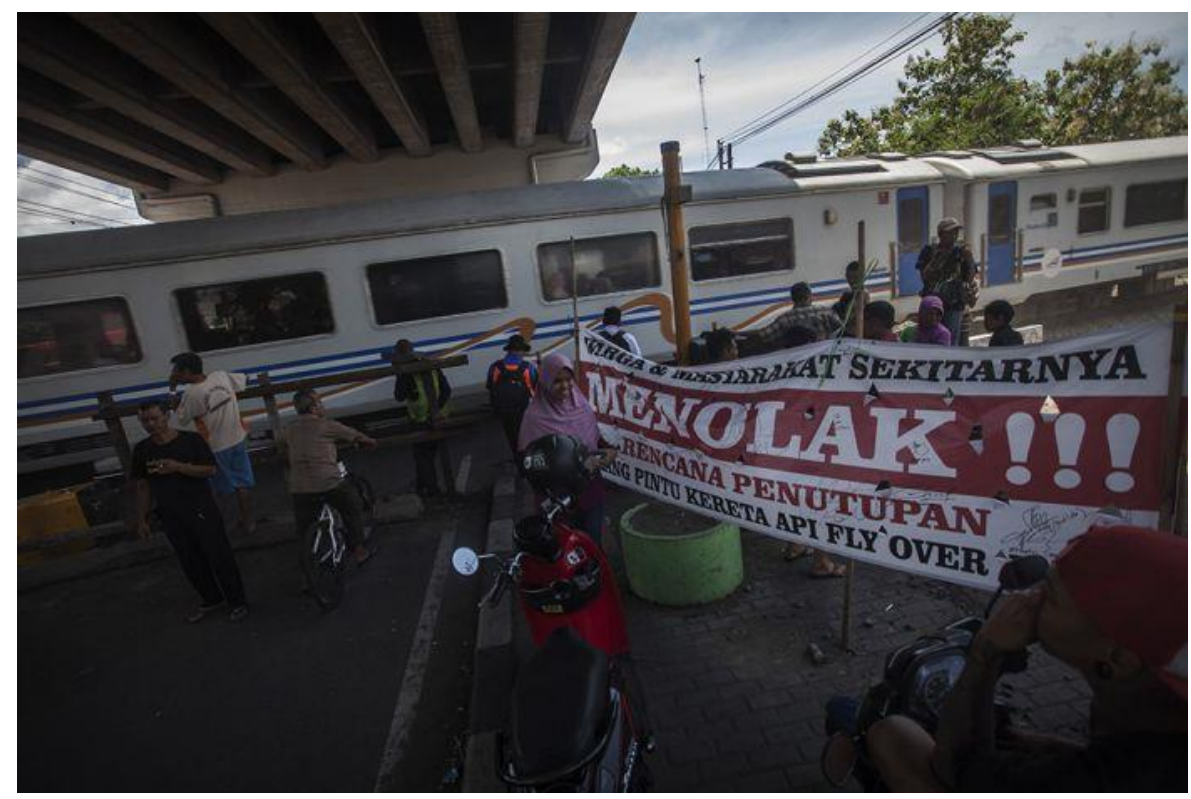

Source: beritagar.id

Penutupan jalan di bawah fly over Janti tersebut mengakibatkan konflik antara masyarakat dengan pemerintah karena matinya sector ekonomi yang berada di sekitar fly over. Kemacetan berhasil teratasi, kepaadatan lalu lintas mampu diuraikan, namun masalah di bidang social yang kemudian muncul adalah penggunaan Kawasan di bawah fly over tersebut sebagai tempat berjualan pada malam hari. (Sigit, 2019) menyebutkan bahwa penutupan akses jalan di bawah Janti fly over sudah berjalan selama 2 tahun namun konflik yang terjadi di masyarakat masih belum usai. Keberadaan fly over Janti juga memancing timbulnya anak jalanan dan gelandangan yang menempati lahan di 
bawah fly over. Gerobak pedagang kaki lima juga sering ditemui di bawah fly over Janti tersebut yang menjadikan tempat ini menjadi kumuh dan tidak terawat.

Pernyataan Direktorat Jendral Perkeretaapian (DJKA) Bersama dengan Dinas Perhubungan Daerah Istimewa Yogyakarta, penutupan jalan yang terjadi di bawah fly over dikarenakan alasan kelancaran mobilitas dan keselamatan berlalu lintas. Adanya jalan sebidang antara jalan utama Janti dengan rel kereta api ini mengkhawatirkan pihak pemantau perkeretaapian karena sudah memakan banyak korban di lintasan rel kereta tersebut. Dalam mempertimbangkan hal itu, pemerintah akhirnya menyetujui untuk menutup jalan sebidang tersebut dikarenakan sudah tersedianya jalan tidak sebidang yakni fly over Janti. Keberadaan fly over Janti juga bertujuan untuk mengurai kemacetan yang terjadi pada jalan sebidang antara jalan utama, persimpangan, dan jalur rel kereta api.

Berdsarkan teori efektivitas untuk mengukur keberhasilan suatu program dapat dinilai dari pencapaian tujuan kebijakan, pencapaian sasaran kebijakan, dan pencapaian hasil kebijakan. Dalam hal pembangunan fly over Janti, hal ini telah memenuhi aspek pencapaian saasaran kebijakan. Kebijakan untuk mengatur mobilitas agar memperlancar arus kendaraan di persimpangan Janti, sudah mampu diwujudkan dengan keberadaan fly over Janti. Dengan begitu maka kemacetan berhasil diminimalisir, terlebih dengan adanya penutupan jalan di bawah area fly over. Namun jika berkaitan dengan sasaran kebijakan, justru penutupan jalan di bawah fly over Janti ini dinilai tidak tepat sasaran. Hal ini dikarenakan adanya konflik yang terjadi antara masyarakat dengan pemerintah dengan tuntutan membuka kembali jalur yang berada di bahwa fly over. Protes masyarakat ini tertuju kepada Dinas Perhubungan Daerah Istimewa Yogyakarta. Namun (Sigit, 2019) menyatakan bahwa penutupan jalan di bawah fly over bukan merupakan kewenangan dari Dinas Perhubungan Daerah Istimewa Yogyakarta, melainkan kewenangan dari Direktorat Jendral Perkeretaapian (DJKA).

\section{PENUTUP}

Tujuan pembangunan fly over dimaksudkan untuk mengatasi permasalahan lalu lintas yakni kepadatan kendaraan bermotor yang melintasi suatu persimpangan, dimana pelebaran jalan tidak mungkin dilakukan karena kondisi alam yang tidak mendukung. Dampak positif dari pembangunan fly over adalah terciptanya kinerja lalu lintas dan menyelesaikan permasalahan aksesibilitas dan mobilitas. Kecepatan kinerja lalu lintas bisa diatasi dengan pembangunan jembatan layang karena tidak ada lagi keterbatasan akses infrastruktur jalan. Di sisi lain, dampak negative pembangunan jembatan layang pada suatu perkotaan memicu daya tarik masyarakat untuk menggunakan kendaraan pribadi yang apabila tidak ada pembatasan regulasi, hal ini akan mengakibatkan kemacetan lalu lintas lagi. Selain itu, daerah di bawah fly over juga berpotensi menjadi daerah kumuh karena digunakan oleh pedagang liar maupun gelandangan.

Untuk itu maka perlu adanya sebuah pengkajian ulang mengenai regulasi yang telah diterapkan oleh pemerintah Kota Yogyakarta. Dalam perwujudan smart city pada bidang smart mobility, aspek yang harus dicapai bukan saja kemudahan akses transportasi, melainkan ada aspek lain seperti keamanan dan 
kenyamanan. Penutupan jalan vertical sebidang di bawah fly over Janti ini menimbulkan ketidak nyamanan warga yang bermukin di area tersebut sehingga dapat dikatakan bahwa pembangunan fly over serta penutupan jalan ini mengakibatkan keresahan dan ketidaknyamanan bagi warganya. Sehingga konsep smart mobility belum mampu berjalan optimal hanya dengan pengadaan infrastruktur jalan yang memadai.

Rekomendasi bagi penelitian selanjutnya adalah untuk mengkaji lebih jauh mengenai regulasi yang berkaitan dengan mobilisasi arus kendaraan bermotor di area fly over Janti. Saran lain untuk pemerintah agar penelitian ini dapat menjadi bahan evaluasi kebijakan yang telah diterapkan maupun proses pembuatan kebijakan yang akan diterapkan.

\section{DAFTAR PUSTAKA}

Arman Syah Putra. (n.d.). SMART CITY: GANJIL GENAP SOLUSI ATAU MASALAH DI DKI JAKARTA. 3(129), 1-10.

Aryandi, R. D., \& Munawar, A. (2014). Penggunaan Software Vissim Untuk Analisis Simpang Bersinyal (Studi Kasus: Simpang Mirota Kampus Terban Yogyakarta). The 17th FSTPT International Symposium, 2(1), 338-347.

Boru, J. El. (n.d.). Analisis Pengaruh Pembangunan Jalan Layang Janti.

Bruce, 2011. (2013). Smart Cities as Democratic Ecologies. In Journal of Chemical Information and Modeling (Vol. 53). https://doi.org/10.1017/CBO9781107415324.004

Darmawan, E. (2018). PERKEMBANGAN SMART CITY KOTA TANJUNGPINANG Eki Darmawan. Jurnal Ilmu Pemerintahan, 2(02), 60-78.

Fauzan, R. (2017). Matra pembaruan. Jurnal Matra Pembaruan, 1(Inovasi kebijakan), 75-84.

Fritz Akhmad Nuzir, R. S. (2015). Smart People, Smart Mobility. (September). https://doi.org/10.13140/RG.2.1.3056.4324

Gunartin, G. (2018). Analisa Faktor-Faktor Kendala Ketercapaian Smart Mobility Dalam Upaya Menuju Konsep Smart City (Studi Pada Kota Tangerang Selatan). Inovasi, 5(2), 33. https://doi.org/10.32493/inovasi.v5i2.y2018.p33-41

Hariani, P., Safina, L., \& Syarifuddin, J. (2017). City Smart Transportation Sebagai Strategi Medan Menuju Smart City. Jurnal Pembangunan Perkotaan, 5(2), 50-58.

Hasibuan, A., \& Sulaiman, O. K. (2014). Smart City, Konsep Kota Cerdas Sebagai Alternatif Penyelesaian Masalah Perkotaan Kabupaten/Kota, Di Kota-Kota Besar Provinsi Sumatera Utara. Buletin Utama Teknik, 14(2). Diambil dari http://www.plimbi.com/news/158601/smart-city-konsep-kota-cerdas

Ibnu, M. (2018). Makalah Penjelasan ( explanation ) Mengenai Tingkat Keberhasilan Badan Usaha Milik Desa. (September).

Janu, M. (2010). Analisis dampak sosial dan ekonomi dalam pembangunan. Pelita, $X, 11-24$.

Khosyi, Y. A., Nurrohman1, A., \& Fahmi, R. A. (2018). Analisis Pelaksanaan Program Social Enterprise. (5), 1-10.

Monoarfa, H. (2012). Efektivitas dan Efisiensi Penyelenggaraan Pelayanan Publik: Suatu Tinjauan Kinerja Lembaga Pemerintahan. Jurnal Pelangi Imu, Vol 5. 
Nilma. (2015). Jurnal manajemen, strategi bisnis dan kewirausahaan . 9(1), 2630.

Papa, E., \& Lauwers, D. (2015). Smart Mobility: Opportunity or Threat to Innovate Places and Cities? Real Corp 2015, 2(May), 543-550.

Purnomo, E. P., Obisva, G., \& Astutik, Z. A. (2019). Smart Government: The involvement of government towards public services in Yogyakarta for Smart Development. (August), 28-30.

Purnomowati, W., \& Ismini. (2014). Konsep Smart City Dan Pengembangan Pariwisata. Jurnal JIBEKA, 8(1), 65-71.

Raharja, A. M., Bagus, I. G., Dharma, B., Industri, J. T., Teknik, F., Mada, U. G., ... Yogyakarta, N. (2017). Kajian Literatur Simulasi Pengaruh Penerapan Underpass Di Beberapa Persimpangan Lainnya. III.

Shiddekh, M. A. I., \& Suryani, E. (2018). Model Sistem Dinamik Spasial untuk Mengurangi Tingkat Kepadatan Ruas Jalan Utama Kota Surabaya dengan Metode Smart Mobility. Jurnal Teknik ITS, $7(1)$. https://doi.org/10.12962/j23373539.v7i1.28314

Wini Mustikarani, \& Suherdiyanto. (2016). Analisis Faktor-Faktor Penyebab Kemacetan Lalu Lintas Di Sepanjang Jalan H Rais a Rahman (Sui Jawi) Kota Pontianak. Jurnal Edukasi, 14(1), 143-155. 